\title{
The Role of Mental Well-Being and Perceived Parental Supportiveness in Adolescents' Problematic Internet Use: Moderation Analysis
}

Juwon Hwang ${ }^{1}$, BA, MA, PhD; Catalina L Toma ${ }^{2}$, BA, MSc, PhD

${ }^{1}$ School of Media and Strategic Communication, Oklahoma State University, Stillwater, OK, United States

${ }^{2}$ Department of Communication Arts, University of Wisconsin-Madison, Madison, WI, United States

Corresponding Author:

Juwon Hwang, BA, MA, PhD

School of Media and Strategic Communication

Oklahoma State University

317-A Paul Miller Building

Stillwater, OK, 74078

United States

Phone: 16083324571

Email: juwon.hwang.23@gmail.com

\section{Abstract}

Background: Given the growing number of adolescents exhibiting problematic internet use (PIU) and experiencing its harmful consequences, it is important to examine the factors associated with PIU. Existing research has identified perceived parental supportiveness and adolescents' subjective mental well-being as strong predictors of PIU. However, it is unknown how these factors work together in shaping adolescents' engagement in PIU.

Objective: This paper aimed to examine the role played by adolescents' perception of parental supportiveness in conjunction with their subjective mental well-being in shaping their PIU.

Methods: The study analyzed one of the Technology \& Adolescent Mental Wellness (TAM) data sets that were collected from a nationally representative cross-sectional sample. Adolescents self-reported their internet use behavior, perceived parental supportiveness, and subjective mental well-being through an online research panel survey. Hierarchical linear regression analysis with an interaction term was performed.

Results: A total of 4592 adolescents, aged 12 to 17 years, completed the survey. Adolescents reported a mean age of 14.61 (SD 1.68 ) and were $46.4 \%$ (2130/4592) female and 66.9\% (3370/4592) White. Findings revealed that, controlling for adolescents' demographics and social media use, higher levels of perceived parental supportiveness $(\beta=-.285, P<.001)$ and higher levels of subjective mental well-being $(\beta=-.079, P<.001)$ were associated with a lower likelihood of adolescent PIU. The moderation analysis showed that the negative association between perceived parental supportiveness and PIU was stronger when adolescents reported high (vs low) levels of mental well-being $(\beta=-.191, P<.001)$.

Conclusions: This study shows that perceived parental supportiveness was a stronger protective factor than adolescents' mental well-being against PIU. The protective power of perceived parental supportiveness against PIU was strongest when adolescents had high mental well-being. The highest risk of PIU occurred when adolescents' mental well-being was high, but parents were perceived as unsupportive. Our findings suggest that parental supportiveness should be targeted as part of PIU prevention efforts.

(JMIR Ment Health 2021;8(9):e26203) doi: $\underline{10.2196 / 26203}$

\section{KEYWORDS}

problematic internet use; PIU; subjective mental well-being; perceived parental supportiveness; adolescents; well-being; young adult; internet; mental health; support; parent; engagement; social media 


\section{Introduction}

\section{Background}

Internet use has become a major part of adolescents' daily life. A recent survey indicates that $45 \%$ of US adolescents aged 13 to 17 years are on the internet almost constantly [1], a figure that has nearly doubled from the $24 \%$ who reported being online on a near-constant basis in 2014-2015 [2]. Moderate internet use can be beneficial to adolescent development by facilitating social connectedness, providing useful information and entertainment, and helping with instrumental tasks (eg, [3,4]). However, excessive internet use can cause serious side effects, such as physical impairment, interpersonal problems, and poor academic performance $[5,6]$.

A growing literature has conceptualized excessive internet use that leads to negative consequences in users' lives as problematic internet use (PIU) [6,7]. Despite some disagreement on terminology and defining criteria [8], PIU is generally described as users' excessive preoccupation with and loss of control over their internet use, resulting in negative personal and professional consequences [6,7]. Internet use refers to accessing the internet for information, entertainment, social connectedness, or other purposes using any device [9].

Adolescence is a particularly vulnerable period for the onset of PIU [10] because adolescents tend to exhibit lower levels of self-regulation [11]. Given the rewarding nature of internet use, low self-regulation is associated with increased risk for PIU [11-15]. In fact, one study found that PIU is more likely to occur in adolescents than in any other population [16]. Adolescent PIU is especially detrimental because it is likely to co-occur with other risky behaviors such as alcohol and drug use [10]. Thus, untreated adolescent PIU may transform into serious internet addiction in adulthood [15]. Given the prevalence and adverse outcomes of PIU among adolescents, it is important to identify the factors associated with PIU in this population. Below, we detail how two key factors-perceived parental supportiveness and adolescents' subjective well-being-are expected to shape the development of adolescent PIU, separately and jointly.

\section{Perceived Parental Supportiveness and PIU}

Adolescents are embedded into a family system that exercises tremendous influence over their lives. Thus, an extensive literature has examined adolescent PIU in the context of family interactions, especially parental supportiveness. Parental supportiveness is defined as "the extent to which parents intentionally foster individuality, self-regulation, and self-assertion by being attuned, supportive, and acquiescent to children's special needs and demands" ([17]; see also Eastin et al [18]). Supportive parents provide meaningful explanations when setting limits and prohibitions on behavior, as well as unconditional positive regard for the child even when behavior does not match parents' expectations or desires [19]. As a result, parental supportiveness helps children internalize and embrace their parents' rules and values, thereby engaging in more prosocial behaviors [20,21]. Parental supportiveness has been shown to be key in promoting adolescents' healthy social behaviors, such as volunteering and donating [21], and decreasing their problematic behaviors, such as cyberbullying [20] and affiliating with a deviant peer [22].

In the context of PIU, studies with US, European, and Asian samples show that supportive parenting practices, as indicated by high parent-child cohesion [23], high-quality parental relationships [24], parent-child bonding [25], and supportive parental monitoring [26], are protective factors against adolescent PIU. By the same token, unsupportive parental practices, as indicated by love withdrawal [27], authoritarian parenting style [28], high parent-child conflict [26], and rejecting, overprotective, or demanding parenting [28], substantially contribute to the development of adolescent PIU. Theoretically, the role played by parental supportiveness in the development of adolescent PIU has been explained through a compensation mechanism [29,30], whereby supportive parenting provides adolescents with a safe haven for sociopsychological development, but unsupportive parenting acts as a significant stressor, prompting adolescents to seek validation, support, and higher-quality relationships on the internet. In turn, adolescents' reliance on the internet for compensating for deficits in parental supportiveness [29] can lead to overuse and compulsive use, the hallmarks of PIU [6-8]. An additional benefit of supportive parenting is that it improves adolescents' emotional regulation skills, making it less likely that they will develop problems with impulse control $[31,32]$.

An important note is that it is possible that unsupportive parents perceive themselves as supportive regardless of how the adolescents actually feel [33]. Since adolescents' compensatory use of the internet is driven by their own perceptions of the family environment, this construct should be measured from the adolescents' perspective. Hence, we hypothesize:

\section{Hypothesis 1: Higher perceived parental supportiveness will be associated with lower PIU among adolescents.}

\section{Subjective Mental Well-Being and PIU}

Mental health can be conceptualized along two dimensions: psychopathology and subjective well-being [34]. Psychopathology refers to a severe disturbance in individuals' actions, emotions, motivations, and cognitive and regulatory processes, causing distress and impairment in daily functioning [35]. Psychopathology is professionally diagnosed and includes disorders such as depression and anxiety. Subjective mental well-being, on the other hand, refers to the extent to which individuals experience optimal psychological functioning and a sense of thriving in their everyday life [36]. Subjective mental well-being includes an affective component (ie, the extent to which individuals experience positive, as opposed to negative, affect in everyday life) and a cognitive component (ie, the extent to which individuals are satisfied with their lives and feel agentic in tackling the challenges of everyday life) [36]. High subjective well-being is the result of high levels of positive affect, low levels of negative affect, and a high assessment of one's own functioning.

While the two perspectives of mental health (ie, psychopathology and mental well-being) are related to each other, they are nonetheless distinct [34]. Simply put, the absence 
of mental illness does not mean individuals experience optimal psychological functioning and thriving. For example, it is possible that a nondepressed person (ie, absence of psychopathology) experiences low levels of positive affect in everyday life and may be dissatisfied with current life circumstances (ie, low subjective mental well-being).

An extensive literature has investigated the connections between adolescents' mental health and their PIU, focusing primarily on psychopathology indicators such as depression and anxiety, and finding that they are significant risk factors for the development of adolescent PIU [12,37-40]. Recently, studies have turned their attention to dimensions of subjective mental well-being, given that these are more applicable to the broad population, as opposed to just clinical samples. Furthermore, PIU is considered a precursor to addiction, and therefore it is not itself an indicator of psychopathology. A similar pattern emerged across international samples, where high subjective mental well-being was robustly associated with low adolescent PIU [41-43], while indicators of low mental well-being, such as low self-esteem [14], self-control [15], and life satisfaction [13], were linked with high adolescent PIU.

High subjective mental well-being is theorized to act as a protective factor against the development of adolescent PIU because high-functioning individuals have more adaptive coping skills when faced with the stressors of daily life and are therefore less likely to turn to the internet to alleviate negative affective states [44]. The experience of sustained positive emotions also enables adolescents to think and act in more flexible and efficient ways, creating a cascade that builds enduring resources, both psychological and interpersonal [45]. Among these resources are better emotional regulation and impulse control, which protect against problematic engagement with the internet [44]. Consistent with these arguments, we hypothesize:

Hypothesis 2: Higher subjective mental well-being will be associated with lower PIU among adolescents.

\section{Interaction Effects of Subjective Mental Well-Being and Perceived Parental Supportiveness on PIU}

While parental supportiveness contributes to high mental well-being among adolescents [46-48], mental well-being is considered a more comprehensive construct that may be related to, but not limited to, parental supportiveness [49]. Indeed, adolescent mental well-being is linked with a variety of other factors, such as the quality of peer relationships [50], peer support [51], sibling relationships [52], teacher caring [53,54], and academic achievement [55]. For example, a social environment with supportive parents but with low-quality peer relationships tends to result in significant impoverishment in adolescents' subjective mental well-being [49].

Both parental supportiveness and mental well-being are expected to be protective factors against adolescent PIU, yet little is known about whether and how these factors work jointly in shaping PIU. We expect that the protective role of perceived parental supportiveness should be stronger for those adolescents with higher subjective mental well-being, since highly functioning adolescents more easily internalize the value and rules of positive social behaviors that their parents try to motivate [20,21]. Not only should adolescents high in subjective well-being be more responsive to parents' supportiveness, thus eschewing PIU, but high parental supportiveness and high subjective well-being indicate a lack of significant stressors in daily life, which should also make it less likely for adolescents to turn to the internet in a compensatory manner. In other words, it is likely that the combination of high perceived parental supportiveness and high mental well-being is least likely to be associated with adolescent PIU.

On the other hand, those with low mental well-being and unsupportive parents should be especially vulnerable to PIU. As reviewed, unsupportive parenting may prompt adolescents to engage in excessive use of the internet [26-28], in an effort to compensate for an invalidating home environment [29,30]. Adolescents with low mental well-being may be more prone to engaging in this maladaptive practice because they lack good coping strategies to deal with stressful situations. Thus, it is likely that the strength of the negative association between parental supportiveness and PIU is weaker among those with low mental well-being than those with high mental well-being. In other words, the combination of low parental supportiveness and low mental well-being should be associated with the highest levels of PIU among adolescents. Thus, we hypothesize:

Hypothesis 3: High subjective mental well-being will
moderate the association between perceived parental
supportiveness and PIU, such that the negative
association between perceived parental
supportiveness and PIU will be stronger for
adolescents with high mental well-being.

\section{Methods}

\section{Data Collection}

The study analyzed one of the Technology \& Adolescent Mental Wellness (TAM) data sets that were collected from a nationally representative cross-sectional sample administered by Qualtrics between March and April 2019. The primary purpose for the data collection was to understand parents' and adolescents' technology use and mental health. The target population was English-speaking US residents aged 12 to 17 years. We set the parameters for Qualtrics to recruit a sample consistent with the race/ethnicity composition of the US census population for 12to 17-year-old subjects. Recruitment and sampling approaches were modeled after previous youth and media studies using Qualtrics [56,57]. This study reports on data provided by adolescents, with the exception of two socioeconomic variables-family income and family structure-which were reported by their parents or guardians. This study was reviewed and approved by the Institutional Review Board at the University of Wisconsin-Madison.

\section{Measures}

\section{Problematic Internet Use}

Adolescents completed the short version of the Problematic and Risky Internet Use Screening Scale (PRIUSS-3) [58]. The PRIUSS-3 was developed based on the PIU conceptual framework [6] and validated for use among adolescents and young adults [58], with strong reliability [59]. The PRIUSS-3 
includes the following items: "how often do you experience increased social anxiety due to your internet use?," "how often do you feel withdrawal when away from the internet?," and "how often do you lose motivation to do other things that need to get done because of the internet?," scored on a 5-point Likert scale from 0 (never) to 4 (very often). Items were summed to create a PIU score for each participant, ranging from 0 to 12 (mean 4.72, SD 3.50; Cronbach $\alpha=.87$ ).

\section{Perceived Parental Supportiveness}

Adolescents answered the following questions about their relationship with their parent or guardian who took the survey with them using a 5-point Likert scale from 0 (never) to 4 (always) [46]: "how often does she/he praise you for doing well?," "how often does she/he criticize you or your ideas?," "how often does she/he help you do things that are important to you?," "how often does she/he blame you for her/his problems?," and "how often does she/he make plans with you and cancel for no good reason?." The questionnaire demonstrated good reliability in previous research [46]. Items were recoded to indicate higher values as higher supportiveness. We removed an item ("how often does she/he criticize you or your ideas?"), which caused weak reliability. Responses were summed to create a score for each participant, ranging from 0 to 16 (mean 12.38, SD 3.2; Cronbach $\alpha=.79$ ).

\section{Subjective Mental Well-Being}

The short version of the Warwick-Edinburgh Mental Well-Being Scale (SWEMWBS) was used to measure adolescents' mental well-being (7 items) [60]. The WEMWBS is a measure of mental well-being focusing entirely on positive aspects of mental health and shows strong criterion and content validity [60]. Adolescents reported how they felt in the past 2 weeks about the following statements on a scale from 1 (none of the time) to 5 (all of the time): "I've been feeling optimistic about the future," "I've been feeling useful," "I've been feeling relaxed," "I've been dealing with problems well," "I've been thinking clearly," and "I've been able to make up my own mind about things." Responses were summed to produce a score for each participant, ranging from 1 to 30 (mean 22.73, SD 4.35; Cronbach $\alpha=.83$ ).

\section{Socioeconomic and Social Media Use Variables}

Age, gender, race, family income, family structure, school type, and social media use were included as covariates in the analysis. Respondents were asked to indicate their age, ranging from 12 to 17 years. Gender was coded with 1 being female and 2 being male. Race was coded with 1 being Caucasian and 0 being others. School type was categorized into 1 being public schools and 0 being others. Family income was assessed using 12 increasing income ranges ( $1=$ less than $\$ 20,000$ to $12=$ more than $\$ 150,000)$. Family structure was coded with 1 being a parent who is divorced, separated, or widowed and 0 being others. Finally, frequency of checking social media was assessed on a scale from 1 (less than once a week) to 8 (almost constantly) [61].

\section{Analytic Strategy}

The hypotheses were tested through a hierarchical linear regression analysis conducted using the lmSupport package in $\mathrm{R}$ (R Core Team). Perceived parental supportiveness and subjective mental well-being were entered as independent variables and PIU as a dependent variable. We controlled for age, gender, race, family income, family structure, school type, and the frequency of checking social media. Predictors were mean-centered before they were entered in the moderated regression model. Multicollinearity was not an issue, with the variance inflation factor statistic for the predictors ranging from 0.52 to 1.93 .

\section{Results}

A total of 4592 parent-adolescent (aged 12-17 years) dyads completed the survey. Adolescents' mean age was 14.61 (SD 1.68) years, and the sample consisted of $46.4 \% \quad(n=2130)$ females and $66.9 \%(n=3370)$ White individuals. Table 1 presents more descriptive information. Bivariate Pearson correlations among all variables included in this analysis are presented in Table 2 .

Most caregivers identified themselves as a biological parent $(\mathrm{n}=3934,85.7 \%)$, followed by stepparent $(\mathrm{n}=246,5.4 \%)$, parent's partner (living together) $(\mathrm{n}=137,3.0 \%)$, adoptive parent $(n=120,2.6 \%)$, grandparent $(n=106,2.3 \%)$, other relative or guardian $(n=26,0.6 \%)$, and foster parent $(n=12,0.3 \%)$. 
Table 1. Descriptive characteristics $(\mathrm{N}=4592)$.

\begin{tabular}{|c|c|}
\hline Characteristic & Participants \\
\hline Age (years), mean (SD) & $14.61(1.68)$ \\
\hline \multicolumn{2}{|l|}{ Gender, n (\%) } \\
\hline Female & $2130(46.4)$ \\
\hline Male & $2392(52.1)$ \\
\hline Nonbinary gender & $23(0.5)$ \\
\hline Female-to-male transgender & $25(0.5)$ \\
\hline Male-to-female transgender & $5(0.1)$ \\
\hline Prefer not to answer & $17(0.4)$ \\
\hline \multicolumn{2}{|l|}{ Race/ethnicity, n (\%) } \\
\hline White/Caucasian & $3370(66.9)$ \\
\hline Black or African American & $699(15.2)$ \\
\hline American Indian/Alaska Native & $116(2.5)$ \\
\hline Asian & $211(4.5)$ \\
\hline Asian Indian & $17(0.4)$ \\
\hline Other Asian & $7(0.2)$ \\
\hline Native Hawaiian/other Pacific Islander & $36(0.8)$ \\
\hline Multiracial & $221(4.8)$ \\
\hline Other & $31(0.7)$ \\
\hline Prefer not to answer & $82(1.8)$ \\
\hline Latino/Hispanic/Mexican & $101(2.2)$ \\
\hline \multicolumn{2}{|l|}{ Family income $(\mathrm{US} \$)^{\mathbf{a}}, \mathbf{n}(\%)$} \\
\hline Less than $\$ 9,999$ & $235(5.1)$ \\
\hline$\$ 10,000-\$ 19,999$ & $310(6.8)$ \\
\hline$\$ 20,000-\$ 29,999$ & $417(9.1)$ \\
\hline$\$ 30,000-\$ 39,999$ & $441(9.6)$ \\
\hline$\$ 40,000-\$ 49,999$ & $385(8.4)$ \\
\hline$\$ 50,000-\$ 59,999$ & $440(9.6)$ \\
\hline$\$ 60,000-\$ 69,999$ & $306(6.7)$ \\
\hline$\$ 70,000-\$ 79,999$ & $399(8.7)$ \\
\hline$\$ 80,000-\$ 89,999$ & $266(5.8)$ \\
\hline$\$ 90,000-\$ 99,999$ & $322(7.0)$ \\
\hline$\$ 100,000-\$ 149,999$ & $694(15.1)$ \\
\hline More than $\$ 150,000$ & $368(8.0)$ \\
\hline \multicolumn{2}{|l|}{ Family structure $^{\mathrm{a}}, \mathbf{n}(\%)$} \\
\hline Married & $2921(63.6)$ \\
\hline Living with a partner & $440(9.6)$ \\
\hline Divorced & $389(8.5)$ \\
\hline Separated & $136(3.0)$ \\
\hline Widowed & $94(2.0)$ \\
\hline Never married & $568(12.4)$ \\
\hline Prefer not to answer & $44(1.0)$ \\
\hline
\end{tabular}




\begin{tabular}{ll}
\hline Characteristic & Participants \\
\hline School type, $\mathbf{n}(\%)$ & $3585(78.1)$ \\
Public school (middle or high school) & $568(12.4)$ \\
Private school (middle or high school) & $207(4.5)$ \\
Home schooled & $106(2.3)$ \\
Online school & $82(1.8)$ \\
Public 4-year college & $23(0.5)$ \\
Not currently in school & $19(0.4)$ \\
Prefer not to answer & \\
Social media use, mean (SD) & $5.15(2.06)$ \\
Frequency of checking social media &
\end{tabular}

${ }^{\mathrm{a}}$ This item was answered by parents or guardians who took the survey with the adolescents.

Table 2. Pearson correlation coefficients for all variables.

\begin{tabular}{|c|c|c|c|c|c|c|c|c|c|c|}
\hline Variables & 1 & 2 & 3 & 4 & 5 & 6 & 7 & 8 & 9 & 10 \\
\hline 1. Age & $-^{\mathrm{a}}$ & - & - & - & - & - & - & - & - & - \\
\hline 2. Gender & -0.021 & - & - & - & - & - & - & - & - & - \\
\hline 3. Race & $0.059^{\mathrm{b}}$ & $0.065^{\mathrm{b}}$ & - & - & - & - & - & - & - & - \\
\hline 4. Family income & 0.026 & $0.115^{\mathrm{b}}$ & $0.160^{\mathrm{b}}$ & - & - & - & - & - & - & - \\
\hline 5. Family structure & $0.052^{\mathrm{b}}$ & $-0.032^{\mathrm{d}}$ & -0.024 & $-0.218^{\mathrm{b}}$ & - & - & - & - & - & - \\
\hline 6. School type & 0.007 & $-0.058^{\mathrm{b}}$ & $-0.049^{\mathrm{c}}$ & $-0.102^{b}$ & $-0.041^{\mathrm{c}}$ & - & - & - & - & - \\
\hline 7. Frequency of checking social media & $0.047^{\mathrm{c}}$ & $-0.048^{\mathrm{e}}$ & $0.038^{\mathrm{d}}$ & $0.059^{\mathrm{b}}$ & $-0.069^{\mathrm{b}}$ & $-0.069^{\mathrm{b}}$ & - & - & - & - \\
\hline 8. Mental well-being & -0.010 & $0.047^{\mathrm{c}}$ & $0.046^{\mathrm{c}}$ & $0.114^{\mathrm{c}}$ & $-0.036^{\mathrm{d}}$ & -0.004 & -0.005 & - & - & - \\
\hline 9. Parental supportiveness & $0.057^{\mathrm{b}}$ & $-0.081^{\mathrm{b}}$ & 0.011 & $-0.069^{\mathrm{b}}$ & $0.079^{\mathrm{b}}$ & $0.152^{\mathrm{b}}$ & $-0.146^{\mathrm{b}}$ & $0.228^{\mathrm{b}}$ & - & - \\
\hline 10. Problematic internet use & $-0.045^{\mathrm{c}}$ & $0.040^{\mathrm{c}}$ & $0.083^{\mathrm{b}}$ & $0.106^{\mathrm{b}}$ & $-0.066^{\mathrm{b}}$ & $-0.140^{\mathrm{b}}$ & $0.353^{\mathrm{b}}$ & $-0.104^{b}$ & $-0.366^{\mathrm{b}}$ & - \\
\hline
\end{tabular}

${ }^{\text {a }}$ The correlation coefficient is not displayed since it is shown in the asymmetrically diagonal position of the table.

${ }^{\mathrm{b}}$ Correlations significant at the $P=.001$ level.

${ }^{\mathrm{c}}$ Correlations significant at the $P=.01$ level.

${ }^{\mathrm{d}}$ Correlations significant at the $P=.05$ level.

Standardized coefficients, standard errors, and $P$ values for the independent variables and all covariates are summarized in Table 3. PIU was associated with being younger $(\beta=-.072$, $P<.001)$, being White $(\beta=.053, P<.001)$, having a higher family income $(\beta=.050, P=.002)$, attending nonpublic school $(\beta=-.060$, $P<.001)$, and using social media more often $(\beta=.277, P<.001)$.

There was a statistically significant negative relationship between perceived parental supportiveness and PIU ( $\beta=-.275$, $P<.001)$, meaning that adolescents who perceived their parents as more supportive were less likely to engage in PIU. Thus, hypothesis 1 was supported. Similarly, there was a statistically significant negative association between subjective mental well-being and PIU ( $\beta=-.079, P<.001)$, meaning that adolescents with higher levels of subjective mental well-being were less likely to be engaged in PIU. Thus, hypothesis 2 was supported.

A statistically significant interaction effect of perceived parental supportiveness and subjective well-being on PIU also emerged
( $\beta=-.191, P<.001)$, meaning that the protective power of perceived parental supportiveness against PIU was strongest when adolescents had high mental well-being, supporting hypothesis 3 .

Simple slope analyses for the association between perceived parental supportiveness and PIU were calculated at the mean (1 SD) level for subjective mental well-being, using the Johnson-Neyman techniques [62]. At mean - 1 SD of subjective mental well-being, the slope was $b=-.12$, SE 0.02, $t=-4.98$, $P<.001$. At mean $+1 \mathrm{SD}$ of subjective mental well-being, the slope was $\mathrm{b}=-.49$, SE 0.02, $t=-20.88, P<.001$. This revealed that the negative association between perceived parental supportiveness and PIU was significantly stronger for those with high subjective mental well-being than for those with low subjective mental well-being (Figure 1). Thus, the protective power of perceived parental supportiveness against PIU was highest when adolescents had high mental well-being. 
Table 3. Hierarchical regression analysis examining the relationships between problematic internet use, perceived parental supportiveness, and subjective mental well-being $(\mathrm{N}=4592)^{\mathrm{a}}$.

\begin{tabular}{|c|c|c|c|c|}
\hline \multirow[t]{2}{*}{ Variable } & \multicolumn{2}{|c|}{ Problematic internet use } & \multirow[t]{2}{*}{$P$ value } & \multirow[t]{2}{*}{$\Delta R^{2}(\%)\left(\right.$ total $\left.R^{2}=28.5 \%\right)$} \\
\hline & $\beta$ & SE & & \\
\hline Control variables & & & & 22.2 \\
\hline Age & -.072 & 0.032 & $<.001$ & \\
\hline Gender $^{\mathrm{b}}$ & .002 & 0.107 & .90 & \\
\hline Race $^{\mathrm{c}}$ & .053 & 0.115 & $<.001$ & \\
\hline Family income & .050 & 0.016 & .002 & \\
\hline Family structure $^{\mathrm{d}}$ & -.020 & 0.160 & .22 & \\
\hline School type ${ }^{\mathrm{e}}$ & -.060 & 0.135 & $<.001$ & \\
\hline Frequency of checking social media & .277 & 0.027 & $<.001$ & \\
\hline Independent variables & & & & 4.2 \\
\hline Perceived parental supportiveness & -.285 & 0.018 & $<.001$ & \\
\hline Subjective mental well-being & -.079 & 0.011 & $<.001$ & \\
\hline Interactions & & & & 2.2 \\
\hline $\begin{array}{l}\text { Perceived parental supportiveness } \times \text { subjective mental } \\
\text { well-being }\end{array}$ & -.191 & 0.003 & $<.001$ & \\
\hline
\end{tabular}

${ }^{\mathrm{a}}$ All coefficients are standardized. Predictors are mean-centered.

${ }^{\mathrm{b}}$ Female $=1$, male $=2$.

${ }^{\mathrm{c}}$ White $=1$, others $=0$.

${ }^{\mathrm{d}}$ Divorced, separated, or widowed parent $=1$, others $=0$.

${ }^{\mathrm{e}}$ Public school $=1$, others $=0$.

Figure 1. Interaction effect between perceived parental supportiveness and subjective mental well-being on problematic internet use.

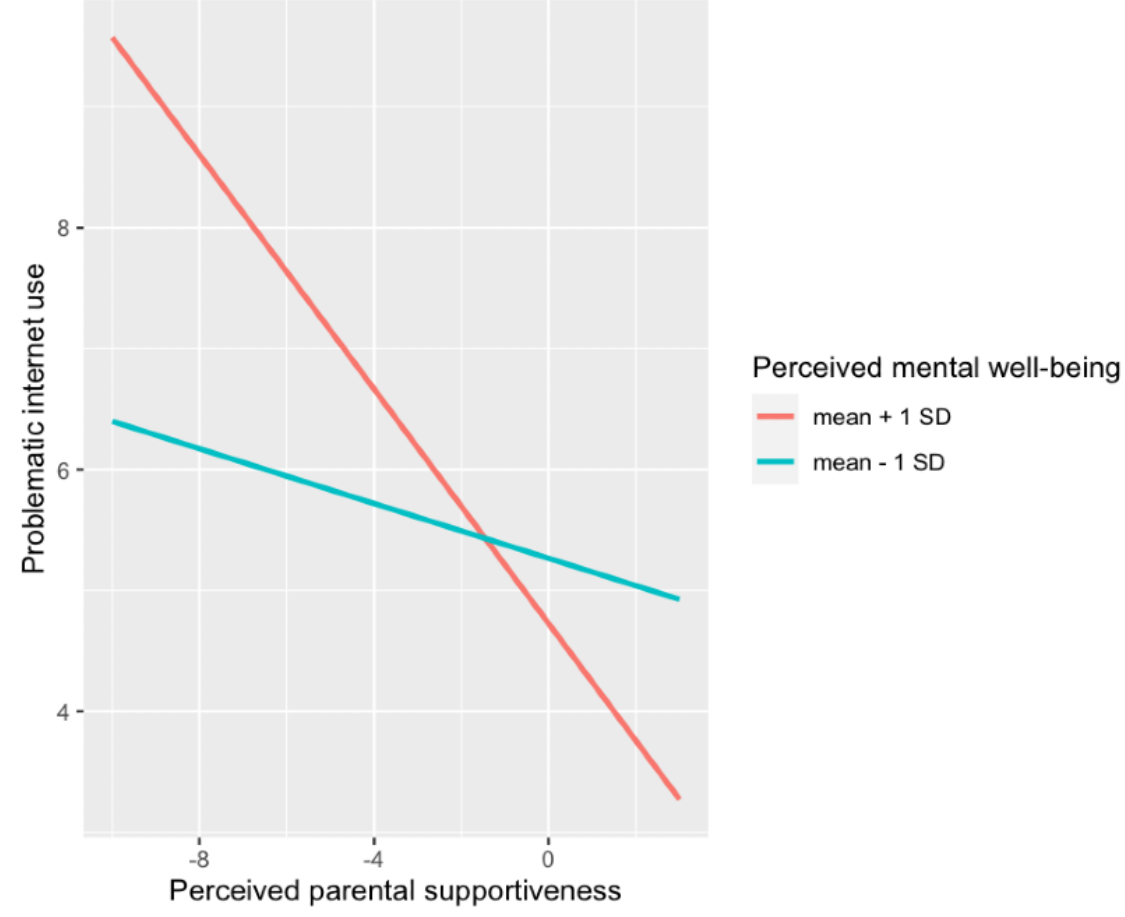




\section{Discussion}

\section{Principal Findings}

PIU among adolescents is a public health concern due to its high prevalence and detrimental impact on adolescents' physical, social, and academic development $[5,6]$. The goal of this study was to examine the role played by two psychological factors in the development of adolescent PIU-perceived parental supportiveness and subjective mental well-being-through a large, nationally representative survey of US adolescents aged 12 to 17 years.

Our main findings can be summarized as follows: the more adolescents perceived their parents as supportive, the less PIU they reported, consistent with research that shows adolescents who perceive their parents as supportive internalize rules and values for prosocial behavior and do not need to resort to internet use to compensate for deficits in parental supportiveness. Similarly, better mental well-being among adolescents was associated with lower PIU, supporting claims by previous research $[44,45]$ that high-functioning individuals have more adaptive coping skills, better emotional regulation, and more internal resources for coping with everyday stressors, without turning to the internet as a refuge or distraction. Notably, the effect of perceived parental supportiveness on PIU was quite large $(\beta=-.278, P<.001)$ and substantially larger than the effect of subjective mental well-being on PIU $(\beta=-.071, P<.001)$, indicating that perceived parental supportiveness may be a key driver of PIU in adolescents, and thus merits attention in future research.

Finally, the negative association between PIU and perceived parental supportiveness increased for adolescents with high mental well-being (Figure 1). PIU was lowest among adolescents with supportive parents and high mental well-being, which indicates that, unsurprisingly, those who are well adjusted and come from supportive environments are protected against risky behaviors such as PIU. However, an unexpected result emerged: PIU was highest among those with unsupportive parents and high mental well-being. While we do not have data on either adolescents' motivations for spending excessive amounts of time on the internet or on the specific activities they undertake online, we have argued that adolescents who perceive their parents as unsupportive turn to the internet to find solace, companionship, and understanding, consistent with the compensation mechanism articulated by prior research $[29,30]$. This finding suggests that it is highly functioning adolescents who are more likely to engage in this compensatory use of the internet. Those who have higher mental well-being may be better attuned to the opportunities provided by the internet to compensate for face-to-face deficits-in our case, a lack of parental supportiveness - and more agentic in pursuing those opportunities. Unfortunately, however, the more time they spend online, likely communicating with peers or seeking other opportunities for fun and relaxation (eg, video games), the more likely they are to rely on the internet to a problematic extent.

We conducted additional analyses to investigate the possibility that adolescents who perceive their parents as unsupportive seek social connections on the internet, potentially in an effort to foster relationships that compensate for low parental supportiveness. A regression model with social media use as the dependent variable and parental supportiveness and mental well-being as independent variables (Multimedia Appendix 1) confirmed that social media use was highest among those with unsupportive parents and high mental well-being. Since social media is a venue for fostering social connections, primarily with peers, this finding provides support for the social compensation hypothesis, whereby teens who perceive their parents as unsupportive parents go online to seek more meaningful social connections (see also Anderson and Jiang [1] and Barker [30]). Initially, this compensatory internet use may be an adaptive practice, but the rewarding nature of the internet can prompt increasing use and overreliance, putting adolescents on a slippery slope toward PIU and later on even internet addiction.

An intriguing issue that should be investigated by future research concerns the interplay between PIU/internet addiction and subjective mental well-being over time. While adolescents with unsupportive parents in our sample maintained high levels of subjective mental well-being even as they engaged in high PIU, it is likely that as PIU continues over time it can lead to a deterioration in subjective mental well-being, and even to psychopathology, supporting the large body of research that finds depression and anxiety to be strongly linked with PIU and internet addiction in young adults [12,37-40]. Although most studies to date are cross-sectional and treat PIU as the outcome of mental health indicators, it is likely that the causal relationship between PIU and mental health is bidirectional, with both variables influencing each other over time. Thus, it is possible that high levels of PIU will, in turn, negatively impact adolescents' mental well-being in the long run.

Given this state of affairs, we argue that adolescence is a tremendously important point for intervention, before PIU turns into full-blown internet addiction and before it leads to a deterioration in adolescents' well-being. Perceptions of parental unsupportiveness were the strongest driver of problematic usage, even among adolescents who otherwise experienced high well-being. Thus, perceived parental supportiveness is a key factor that should be targeted. For example, PIU prevention should include training for parents to improve their communication skills and provide appropriate discipline, but also validation and companionship, for their adolescents.

\section{Limitations and Future Directions}

This study has several limitations. While associations were observed between PIU and subjective mental well-being and perceived parental supportiveness, the cross-sectional nature of the study does not permit insight into temporal or causal relationships. Future longitudinal studies are necessary to understand what factors protect adolescents against PIU. This study did not differentiate between diverse types of internet use (eg, video gaming, chatting, social networking sites, etc). PIU in these different online contexts may relate differently to subjective mental well-being and perceived parental supportiveness. Furthermore, the measures are all self-reported by adolescents and thus are limited by their ability and willingness to recall and report information accurately. 


\section{Conclusion}

Despite these limitations, this study contributes to the literature by finding a meaningful interplay between adolescents' mental well-being and their perception of parental supportiveness in shaping PIU. This helps illuminate the conditions under which adolescent PIU emerges.

\section{Acknowledgments}

Access to secondary data in this study was supported by the TAM Data Consortium at the University of Wisconsin-Madison. The content is solely the responsibility of the authors and does not represent the official views of the university nor the TAM Data Consortium.

\section{Conflicts of Interest}

None declared.

\section{Multimedia Appendix 1}

Interaction effect between subjective mental well-being and perceived parental supportiveness on the frequency of checking social media.

[DOCX File, 89 KB-Multimedia Appendix 1]

\section{References}

1. Anderson M, Jiang J. Teens, Social Media and Technology 2018. Pew Research Center. 2018 May 31. URL: https://www. pewresearch.org/internet/2018/05/31/teens-social-media-technology-2018/ [accessed 2021-06-11]

2. Lenhart A. Pew Research Center. 2015 Apr 9. URL: https://www.pewresearch.org/internet/2015/04/09/ teens-social-media-technology-2015/ [accessed 2021-06-09]

3. Jackson LA, von Eye A, Witt EA, Zhao Y, Fitzgerald HE. A longitudinal study of the effects of Internet use and videogame playing on academic performance and the roles of gender, race and income in these relationships. Computers in Human Behavior 2011 Jan;27(1):228-239. [doi: 10.1016/j.chb.2010.08.001]

4. Liu Q, Fang X, Deng L, Zhang J. Parent-adolescent communication, parental Internet use and Internet-specific norms and pathological Internet use among Chinese adolescents. Computers in Human Behavior 2012 Jul;28(4):1269-1275. [doi: 10.1016/j.chb.2012.02.010]

5. D'Angelo J, Moreno MA. Screening for Problematic Internet Use. Pediatrics 2020 May;145(Suppl 2):S181-S185 [FREE Full text] [doi: 10.1542/peds.2019-2056F] [Medline: $\underline{32358209]}$

6. Moreno MA, Jelenchick LA, Christakis DA. Problematic internet use among older adolescents: A conceptual framework. Computers in Human Behavior 2013 Jul;29(4):1879-1887. [doi: 10.1016/j.chb.2013.01.053]

7. Cheever N, Moreno M, Rosen L. When does internet and smartphone use become a problem? In: Technology and Adolescent Mental Health. Cham: Springer International Publishing; 2018:121-131.

8. Spada MM. An overview of problematic internet use. Addict Behav 2014 Jan;39(1):3-6. [doi: 10.1016/j.addbeh.2013.09.007] [Medline: 24126206]

9. Lai FT, Kwan JL. Socioeconomic influence on adolescent problematic Internet use through school-related psychosocial factors and pattern of Internet use. Computers in Human Behavior 2017 Mar;68:121-136. [doi: 10.1016/j.chb.2016.11.021]

10. Gómez P, Harris SK, Barreiro C, Isorna M, Rial A. Profiles of Internet use and parental involvement, and rates of online risks and problematic Internet use among Spanish adolescents. Computers in Human Behavior 2017 Oct;75:826-833. [doi: 10.1016/j.chb.2017.06.027]

11. Li D, Zhang W, Li X, Zhen S, Wang Y. Stressful life events and problematic Internet use by adolescent females and males: A mediated moderation model. Computers in Human Behavior 2010 Sep;26(5):1199-1207. [doi: 10.1016/j.chb.2010.03.031]

12. Caplan S. Problematic internet use in the workplace. In: The Internet and Workplace Transformation. New York, NY: Routledge; 2006:63.

13. Cao H, Sun Y, Wan Y, Hao J, Tao F. Problematic Internet use in Chinese adolescents and its relation to psychosomatic symptoms and life satisfaction. BMC Public Health 2011 Oct 14;11:802 [FREE Full text] [doi: 10.1186/1471-2458-11-802] [Medline: 21995654]

14. Fioravanti G, Primi C, Casale S. Psychometric evaluation of the Generalized Problematic Internet Use Scale 2 in an Italian sample. Cyberpsychol Behav Soc Netw 2013 Oct;16(10):761-766. [doi: 10.1089/cyber.2012.0429] [Medline: 23742149]

15. Park S, Kang M, Kim E. Social relationship on problematic Internet use (PIU) among adolescents in South Korea: A moderated mediation model of self-esteem and self-control. Computers in Human Behavior 2014 Sep;38:349-357. [doi: 10.1016/j.chb.2014.06.005]

16. Karacic S, Oreskovic S. Internet Addiction Through the Phase of Adolescence: A Questionnaire Study. JMIR Ment Health 2017 Apr 03;4(2):e11 [FREE Full text] [doi: 10.2196/mental.5537] [Medline: 28373154]

17. Baumrind D. The Influence of Parenting Style on Adolescent Competence and Substance Use. The Journal of Early Adolescence 2016 Jul 26;11(1):56-95. [doi: 10.1177/0272431691111004] 
18. Eastin M, Greenberg B, Hofschire L. Parenting the internet. Journal of Communication 2006;56(3):486-504. [doi: 10.1111/j.1460-2466.2006.00297.x]

19. Assor A, Roth G, Deci EL. The emotional costs of parents' conditional regard: a self-determination theory analysis. J Pers 2004 Feb;72(1):47-88. [doi: 10.1111/j.0022-3506.2004.00256.x] [Medline: 14686884]

20. Legate N, Weinstein N, Przybylski AK. Parenting Strategies and Adolescents' Cyberbullying Behaviors: Evidence from a Preregistered Study of Parent-Child Dyads. J Youth Adolesc 2019 Feb;48(2):399-409. [doi: 10.1007/s10964-018-0962-y] [Medline: 30478820]

21. Gagné M. The role of autonomy support and autonomy orientation in prosocial behavior engagement. Motivation and emotion 2003 Sep;27(3):199-223. [doi: 10.1023/A:1025007614869]

22. Soenens B, Vansteenkiste M, Niemiec C. Should parental prohibition of adolescents' peer relationships be prohibited? Personal Relationships 2009 Sep 08;16(4):507-530. [doi: 10.1111/j.1475-6811.2009.01237.x]

23. Park SK, Kim JY, Cho CB. Prevalence of Internet addiction and correlations with family factors among South Korean adolescents. Adolescence 2008;43(172):895-909. [Medline: 19149152]

24. Bleakley A, Ellithorpe M, Romer D. The Role of Parents in Problematic Internet Use among US Adolescents. MaC 2016 Jun 16;4(3):24-34. [doi: 10.17645/mac.v4i3.523]

25. Siomos K, Floros G, Fisoun V, Evaggelia D, Farkonas N, Sergentani E, et al. Evolution of Internet addiction in Greek adolescent students over a two-year period: the impact of parental bonding. Eur Child Adolesc Psychiatry 2012 Apr;21(4):211-219. [doi: 10.1007/s00787-012-0254-0] [Medline: 22311146]

26. Yen J, Yen C, Chen C, Chen S, Ko C. Family factors of internet addiction and substance use experience in Taiwanese adolescents. Cyberpsychol Behav 2007 Jun;10(3):323-329. [doi: 10.1089/cpb.2006.9948] [Medline: 17594255]

27. Li X, Li D, Newman J. Parental behavioral and psychological control and problematic internet use among Chinese adolescents: the mediating role of self-control. Cyberpsychol Behav Soc Netw 2013 Jun;16(6):442-447. [doi: 10.1089/cyber.2012.0293] [Medline: 23509987]

28. Xiuqin H, Huimin Z, Mengchen L, Jinan W, Ying Z, Ran T. Mental health, personality, and parental rearing styles of adolescents with Internet addiction disorder. Cyberpsychol Behav Soc Netw 2010 Aug;13(4):401-406. [doi: 10.1089/cyber.2009.0222] [Medline: 20712498]

29. Valkenburg PM, Peter J. Social Consequences of the Internet for Adolescents. Curr Dir Psychol Sci 2009 Feb 01;18(1):1-5. [doi: 10.1111/j.1467-8721.2009.01595.x]

30. Barker V. Older adolescents' motivations for social network site use: the influence of gender, group identity, and collective self-esteem. Cyberpsychol Behav 2009 Apr;12(2):209-213. [doi: 10.1089/cpb.2008.0228] [Medline: 19250021]

31. Sela Y, Zach M, Amichay-Hamburger Y, Mishali M, Omer H. Family environment and problematic internet use among adolescents: The mediating roles of depression and Fear of Missing Out. Computers in Human Behavior 2020 May;106:106226. [doi: 10.1016/j.chb.2019.106226]

32. Bulanda RE, Majumdar D. Perceived Parent-Child Relations and Adolescent Self-Esteem. J Child Fam Stud 2008 Jul 29;18(2):203-212. [doi: 10.1007/s10826-008-9220-3]

33. McNeely CA, Barber BK. How Do Parents Make Adolescents Feel Loved? Perspectives on Supportive Parenting From Adolescents in 12 Cultures. Journal of Adolescent Research 2010 Jan 27;25(4):601-631. [doi: 10.1177/0743558409357235]

34. Meier A, Reinecke L. Computer-Mediated Communication, Social Media, and Mental Health: A Conceptual and Empirical Meta-Review. Communication Research 2020 Oct 21. [doi: 10.1177/0093650220958224]

35. Lahey BB, Krueger RF, Rathouz PJ, Waldman ID, Zald DH. Validity and utility of the general factor of psychopathology. World Psychiatry 2017 Jun 12;16(2):142-144 [FREE Full text] [doi: 10.1002/wps.20410] [Medline: 28498590]

36. Diener E, Oishi S, Tay L. Advances in subjective well-being research. Nat Hum Behav 2018 Apr 12;2(4):253-260. [doi: 10.1038/s41562-018-0307-6] [Medline: 30936533]

37. Gámez-Guadix M. Depressive symptoms and problematic internet use among adolescents: analysis of the longitudinal relationships from the cognitive-behavioral model. Cyberpsychol Behav Soc Netw 2014 Nov;17(11):714-719 [FREE Full text] [doi: 10.1089/cyber.2014.0226] [Medline: 25405784]

38. Park S, Hong KM, Park EJ, Ha KS, Yoo HJ. The association between problematic internet use and depression, suicidal ideation and bipolar disorder symptoms in Korean adolescents. Aust N Z J Psychiatry 2013 Feb 09;47(2):153-159. [doi: 10.1177/0004867412463613] [Medline: 23047959]

39. Ceyhan AA, Ceyhan E. Loneliness, depression, and computer self-efficacy as predictors of problematic internet use. Cyberpsychol Behav 2008 Dec;11(6):699-701. [doi: 10.1089/cpb.2007.0255] [Medline: 19072150]

40. Tan Y, Chen Y, Lu Y, Li L. Exploring Associations between Problematic Internet Use, Depressive Symptoms and Sleep Disturbance among Southern Chinese Adolescents. Int J Environ Res Public Health 2016 Mar 14;13(3):313 [FREE Full text] [doi: 10.3390/ijerph13030313] [Medline: 26985900]

41. Odacı H, Çıkrıkçı. Problematic internet use in terms of gender, attachment styles and subjective well-being in university students. Computers in Human Behavior 2014 Mar;32:61-66. [doi: 10.1016/j.chb.2013.11.019]

42. Mei S, Yau YH, Chai J, Guo J, Potenza MN. Problematic Internet use, well-being, self-esteem and self-control: Data from a high-school survey in China. Addict Behav 2016 Oct;61:74-79 [FREE Full text] [doi: 10.1016/j.addbeh.2016.05.009] [Medline: 27249805] 
43. Satici B, Yilmaz M. How Does Problematic Internet Use Mediate The Relation Between Belongingness And Mental Well-Being? Turkish Psychological Counseling and Guidance Journal 2020 Jun 19;10(57):277-295 [FREE Full text]

44. Casale S, Lecchi S, Fioravanti G. The association between psychological well-being and problematic use of Internet communicative services among young people. J Psychol 2015;149(5):480-497. [doi: 10.1080/00223980.2014.905432] [Medline: 25975575]

45. Park N. The Role of Subjective Well-Being in Positive Youth Development. The Annals of the American Academy of Political and Social Science 2016 Sep 08;591(1):25-39. [doi: 10.1177/0002716203260078]

46. Hair EC, Moore KA, Garrett SB, Ling T, Cleveland K. The Continued Importance of Quality Parent-Adolescent Relationships During Late Adolescence. J Research on Adolescence 2008 Mar;18(1):187-200. [doi: 10.1111/j.1532-7795.2008.00556.x]

47. Milevsky A, Schlechter M, Netter S, Keehn D. Maternal and Paternal Parenting Styles in Adolescents: Associations with Self-Esteem, Depression and Life-Satisfaction. J Child Fam Stud 2006 Sep 13;16(1):39-47. [doi: 10.1007/s10826-006-9066-5]

48. Bean RA, Barber BK, Crane DR. Parental Support, Behavioral Control, and Psychological Control Among African American Youth. Journal of Family Issues 2016 Jun 30;27(10):1335-1355. [doi: 10.1177/0192513x06289649]

49. Ryan RM, Deci EL. On happiness and human potentials: a review of research on hedonic and eudaimonic well-being. Annu Rev Psychol 2001 Feb;52(1):141-166. [doi: 10.1146/annurev.psych.52.1.141] [Medline: 11148302]

50. McMahon G, Creaven A, Gallagher S. Stressful life events and adolescent well-being: The role of parent and peer relationships. Stress Health 2020 Aug;36(3):299-310. [doi: 10.1002/smi.2923] [Medline: 31920010]

51. Rigby K. Effects of peer victimization in schools and perceived social support on adolescent well-being. J Adolesc 2000 Feb;23(1):57-68. [doi: 10.1006/jado.1999.0289] [Medline: 10700372]

52. Sherman AM, Lansford JE, Volling BL. Sibling relationships and best friendships in young adulthood: Warmth, conflict, and well-being. Personal Relationships 2006 Jun;13(2):151-165. [doi: 10.1111/j.1475-6811.2006.00110.x]

53. LaRusso MD, Romer D, Selman RL. Teachers as Builders of Respectful School Climates: Implications for Adolescent Drug Use Norms and Depressive Symptoms in High School. J Youth Adolescence 2007 Aug 24;37(4):386-398. [doi: $10.1007 / \mathrm{s} 10964-007-9212-4]$

54. DuBois DL, Silverthorn N. Natural mentoring relationships and adolescent health: evidence from a national study. Am J Public Health 2005 Mar;95(3):518-524. [doi: 10.2105/AJPH.2003.031476] [Medline: 15727987]

55. Duncan MJ, Patte KA, Leatherdale ST. Mental Health Associations with Academic Performance and Education Behaviors in Canadian Secondary School Students. Canadian Journal of School Psychology 2021 Feb 25. [doi:

10.1177/0829573521997311]

56. Moreno MA, Binger K, Zhao Q, Eickhoff J. Measuring Interests Not Minutes: Development and Validation of the Adolescents' Digital Technology Interactions and Importance Scale (ADTI). J Med Internet Res 2020 Feb 12;22(2):e16736 [FREE Full text] [doi: $\underline{10.2196 / 16736}$ ] [Medline: $\underline{32049068]}$

57. Heen MS, Lieberman JD, Miethe TD. A Comparison of Different Online Sampling Approaches for Generating National Samples. Center for Crime and Justice Policy. Nevada, LV: University of Nevada, Las Vegas; 2014. URL: https://www. unlv.edu/sites/default/files/page files/27/ComparisonDifferentOnlineSampling.pdf [accessed 2021-06-18]

58. Moreno MA, Arseniev-Koehler A, Selkie E. Development and Testing of a 3-Item Screening Tool for Problematic Internet Use. J Pediatr 2016 Sep;176:167-172.e1 [FREE Full text] [doi: 10.1016/j.jpeds.2016.05.067] [Medline: 27395768]

59. Jelenchick L, Hawk S, Moreno M. Problematic internet use and social networking site use among Dutch adolescents. Int J Adolesc Med Health 2016 Feb;28(1):119-121. [doi: 10.1515/ijamh-2014-0068] [Medline: 25720115]

60. Tennant R, Hiller L, Fishwick R, Platt S, Joseph S, Weich S, et al. The Warwick-Edinburgh Mental Well-being Scale (WEMWBS): development and UK validation. Health Qual Life Outcomes 2007 Nov 27;5:63 [FREE Full text] [doi: 10.1186/1477-7525-5-63] [Medline: 18042300 ]

61. Primack BA, Shensa A, Sidani JE, Whaite EO, Lin LY, Rosen D, et al. Social Media Use and Perceived Social Isolation Among Young Adults in the U.S. Am J Prev Med 2017 Jul;53(1):1-8 [FREE Full text] [doi: 10.1016/j.amepre.2017.01.010] [Medline: 28279545]

62. Johnson PO, Neyman J. Tests of certain linear hypotheses and their application to some educational problems. Statistical Research Memoirs 1936;1:57-93.
Abbreviations
PIU: problematic internet use
PRIUSS-3: Problematic and Risky Internet Use Screening Scale
SWEMWBS: Warwick-Edinburgh Mental Well-Being Scale-short version
TAM: Technology \& Adolescent Mental Wellness
WEMWBS: Warwick-Edinburgh Mental Well-Being 
Edited by A Jolliff; submitted 01.12.20; peer-reviewed by J D'Angelo, D Bickham; comments to author 19.01.21; revised version received 22.03.21; accepted 14.04.21; published 15.09.21

Please cite as:

Hwang J, Toma CL

The Role of Mental Well-Being and Perceived Parental Supportiveness in Adolescents' Problematic Internet Use: Moderation Analysis JMIR Ment Health 2021;8(9):e26203

URL: https://mental.jmir.org/2021/9/e26203

doi: $10.2196 / 26203$

PMID: $\underline{34524093}$

(CJuwon Hwang, Catalina L Toma. Originally published in JMIR Mental Health (https://mental.jmir.org), 15.09.2021. This is an open-access article distributed under the terms of the Creative Commons Attribution License (https://creativecommons.org/licenses/by/4.0/), which permits unrestricted use, distribution, and reproduction in any medium, provided the original work, first published in JMIR Mental Health, is properly cited. The complete bibliographic information, a link to the original publication on https://mental.jmir.org/, as well as this copyright and license information must be included. 